\title{
The Deployable Fast-Neutron Coded- Aperture Imager: Demonstration of Locating One or More Sources in Three Dimensions
}

September 2013

Prepared by

Paul Hausladen Jason Newby Felix Liang Matthew Blackston 


\section{DOCUMENT AVAILABILITY}

Reports produced after January 1, 1996, are generally available free via US Department of Energy (DOE) SciTech Connect.

Website http://www.osti.gov/scitech/

Reports produced before January 1, 1996, may be purchased by members of the public from the following source:

National Technical Information Service

5285 Port Royal Road

Springfield, VA 22161

Telephone 703-605-6000 (1-800-553-6847)

TDD 703-487-4639

Fax 703-605-6900

E-mail info@ntis.gov

Website http://www.ntis.gov/support/ordernowabout.htm

Reports are available to DOE employees, DOE contractors, Energy Technology Data Exchange representatives, and International Nuclear Information System representatives from the following source:

Office of Scientific and Technical Information

PO Box 62

Oak Ridge, TN 37831

Telephone 865-576-8401

Fax 865-576-5728

E-mail reports@osti.gov

Website http://www.osti.gov/contact.html

This report was prepared as an account of work sponsored by an agency of the United States Government. Neither the United States Government nor any agency thereof, nor any of their employees, makes any warranty, express or implied, or assumes any legal liability or responsibility for the accuracy, completeness, or usefulness of any information, apparatus, product, or process disclosed, or represents that its use would not infringe privately owned rights. Reference herein to any specific commercial product, process, or service by trade name, trademark, manufacturer, or otherwise, does not necessarily constitute or imply its endorsement, recommendation, or favoring by the United States Government or any agency thereof. The views and opinions of authors expressed herein do not necessarily state or reflect those of the United States Government or any agency thereof. 
ORNL/TM-2013/446

Nuclear Security and Isotope Technology Division

\title{
THE DEPLOYABLE FAST-NEUTRON CODED-APERTURE IMAGER: DEMONSTRATION OF LOCATING ONE OR MORE SOURCES IN THREE DIMENSIONS
}

Paul Hausladen, Jason Newby, Felix Liang, and Matthew Blackston

Date Published: September 2013

\author{
Prepared by \\ OAK RIDGE NATIONAL LABORATORY \\ Oak Ridge, Tennessee 37831-6283 \\ managed by \\ UT-BATTELLE, LLC \\ for the \\ U.S. DEPARTMENT OF ENERGY \\ under contract DE-AC05-00OR22725
}





\section{CONTENTS}

\section{Page}

LIST OF FIGURES

V

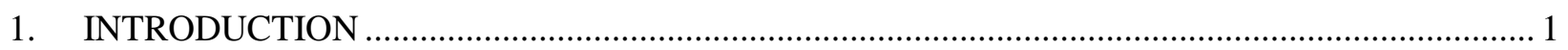

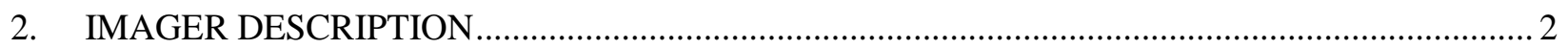

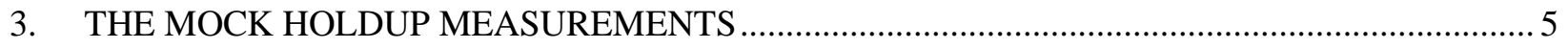

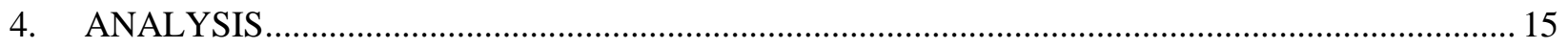

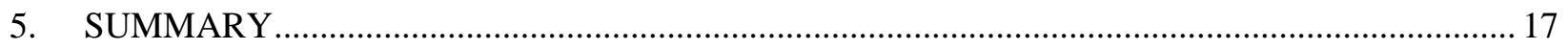

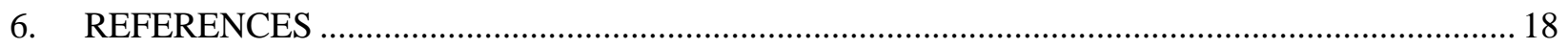





\section{LIST OF FIGURES}

Page

Fig. 1. The fast-neutron imager: (a) a schematic diagram identifying the aperture, detector, linear stage, and camera components, (b) a photograph of the imager from the same view, and (c) a photograph of the imager from the front, showing the aperture mask and camera........... 2

Fig. 2. The components and assembly of a single detector module..................................................... 3

Fig. 3. Photographs of the large L-duct, HEPA filter house, and pipe array used for mock holdup measurements.

Fig. 4. Layout of the mock holdup measurement scene............................................................... 6

Fig. 5. A composite view of the first scene: (above) photograph and (below) depth image........................ 7

Fig. 6. Individual coded-aperture images as a function of distance from the imager for a slice in

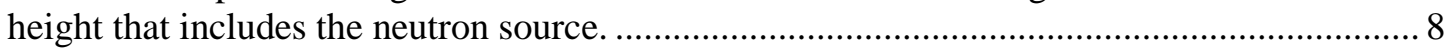

Fig. 7. A combined image of the nine individual measurements for scene 1 . ..................................... 9

Fig. 8. A combined image of the nine individual measurements for scene 2 . .................................... 10

Fig. 9. Composite view of scene 3 with the positions of the neutron sources indicated by the red

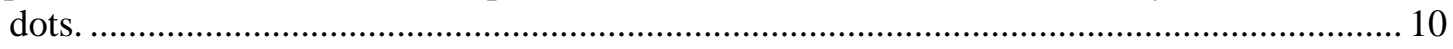

Fig. 10. A combined image of the nine individual measurements for scene 3.................................... 11

Fig. 11. A combined image of the nine individual measurements for scene 4. .................................... 12

Fig. 12. Composite view of scene 5 with the positions of the neutron sources indicated by the red

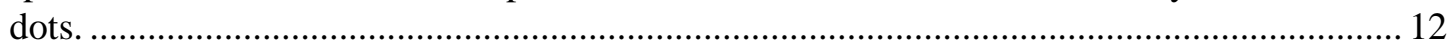

Fig. 13. A combined image of the nine individual measurements for scene 5 ..................................... 13

Fig. 14. A combined image of the nine individual measurements for scene 6 . ................................... 14

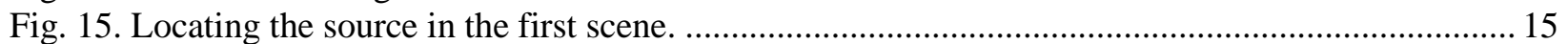

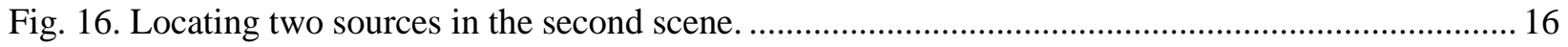





\section{INTRODUCTION}

This brief report describes commissioning measurements performed using a newly constructed fastneutron coded-aperture imager intended for performing quantitative measurements of plutonium holdup at fuel cycle facilities. The present report was prepared in fulfillment of milestone M3FT-13OR0402054, "Imager commissioning and 3D source configuration measurements" of Fuel Cycle R\&D Material Protection, Accounting, and Control Technology (MPACT) work package FT-13OR040205, "FastNeutron Imaging to Quantify Nuclear Materials - ORNL." In addition to representing the first measurements made with the new device, these measurements also demonstrate for the first time the ability to localize one or more neutron sources in three dimensions by combining imaging data from multiple measurements in which the imager was positioned at different locations.

The development and use of fast-neutron imaging technology are motivated by a desire to locate and quantify plutonium holdup in scenarios where contact measurements with non-imaging detectors may be impractical or their results ambiguous because of surrounding material or nearby sources. Considering the goal of quantitative measurements, fast neutrons (as opposed to the more numerous gamma rays) are preferred in many situations because of their ability to penetrate equipment and nuclear material that are essentially opaque to gamma radiation. However, there are many challenges associated with constructing a practical imager for fast neutrons. For example, the ability of fast neutrons to penetrate material also leads to challenges in constructing a fast-neutron imager that is sufficiently compact to be suitable for use in a facility while remaining sufficiently sensitive to neutron emanations from plutonium or other actinides. Moreover, use of the imager in a production environment favors mechanically robust detectors that do not contain flammable liquid, unlike the organic liquid scintillators that are typically used to achieve fast-neutron detection. Last of all, a single-sided measurement geometry, as is typically used in imaging applications, necessitates accurate measurement of the location of a deposit of plutonium holdup in three dimensions in order to correctly infer the source strength. In response to these challenges, Oak Ridge National Laboratory (ORNL) has built a fast-neutron imager that has a compact footprint and whose segmented neutron detectors are built from the first cast plate of the recently developed plastic scintillator with pulse shape discrimination properties developed by Lawrence Livermore National Laboratory and commercially available from Eljen Technologies as experimental scintillator EJ-299-34 [1]. This report presents a description and preliminary analysis of mock holdup measurements intended to determine the three-dimensional location of one or more neutron sources placed in prototypical equipment from a set of imaging measurements that scanned the extent of the equipment. 


\section{IMAGER DESCRIPTION}

While the new imager has been reported on previously [2], a brief description of it is included in the present report for clarity.

Following the construction and use of a previous fast-neutron imager built at ORNL $[3,4]$, the need for a more compact and robust imager that could withstand shipment to and from and use in a fuel cycle facility was apparent. While successful as a laboratory device, the previous imager was large and unwieldy, and the neutron detectors (whose active volume consisted of commercially available liquid scintillator EJ-309) were fragile and sensitive to mechanical shock and temperature changes that were relatively modest. Like the previous imager, the new imager consists of an aperture mask and a positionsensitive fast-neutron imaging detector whose relative positions are set with a linear stage in order to adjust the field of view. A schematic diagram of the major imager components is shown in Fig. 1(a), and a corresponding photograph of the imager is shown in Fig. 1(b). The linear stage adjusts the maskdetector separation between a minimum of $23 \mathrm{~cm}$ and a maximum of $44 \mathrm{~cm}$ (measured from the center of the detector active volume to the center of the mask). The total length of the imager is $121 \mathrm{~cm}$ (when the mask-detector separation is less than $28 \mathrm{~cm}$ ). At larger mask-detector separations, the electronics module protrudes from the back of the imager and increases the length of the imager to a maximum of $137 \mathrm{~cm}$ at maximum mask-detector separation. Note that with the present neutron detector module length of $50 \mathrm{~cm}$, a mask-detector separation of $40 \mathrm{~cm}$, and a mask thickness of $10 \mathrm{~cm}$, it would be difficult to make the scale of the imager smaller than $1 \mathrm{~m}$. The mask assembly can be rotated about its vertical axis in order to fit through a standard (36 in.) doorway. A photograph of the imager from the front in which the aperture pattern is visible is shown in Fig. 1(c), along with the Microsoft Kinect ${ }^{\circledR}$ camera mounted on a thin carbon fiber rod in front of the mask. The camera will be discussed later in this section.

(a)

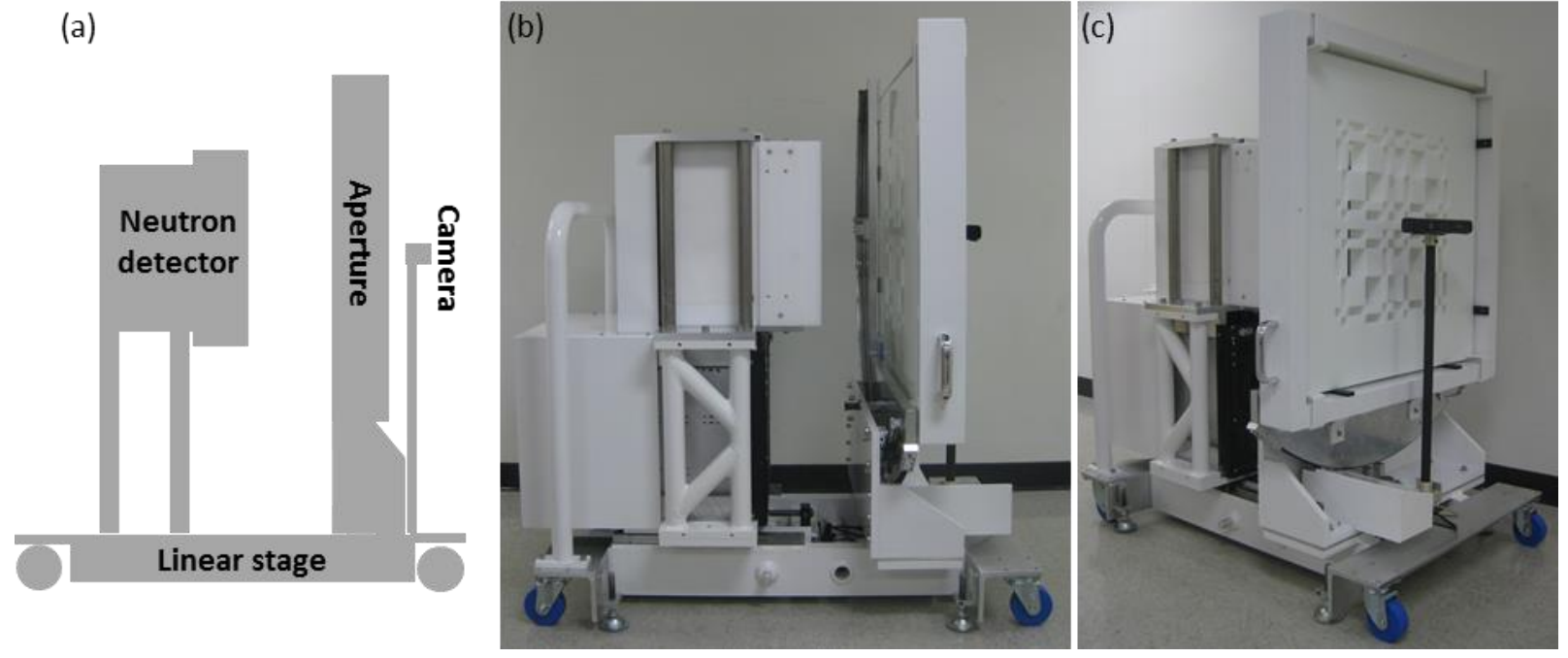

Fig. 1. The fast-neutron imager: (a) a schematic diagram identifying the aperture, detector, linear stage, and camera components, (b) a photograph of the imager from the same view, and (c) a photograph of the imager from the front, showing the aperture mask and camera.

The aperture mask chosen for the imager is a rank-11 modified uniformly redundant array (MURA) coded aperture constructed of high-density polyethylene (HDPE) [5]. The mask pattern was machined in each of three $81 \mathrm{~cm} \times 81 \mathrm{~cm} \times 2.54 \mathrm{~cm}$ pieces of HDPE that can be stacked to yield a thickness up to 7.6 $\mathrm{cm}$. The holder for the mask can accommodate mask thicknesses up to $10 \mathrm{~cm}$. In the selected aperture pattern, the size of the 11-element base pattern is $26.7 \mathrm{~cm}$. Using a rank-11 MURA, the field of view is divided into an $11 \times 11$ grid of uniquely identifiable basis directions. Consequently, the inherent 
resolution of such a mask corresponds to the field of view divided by the mask rank. The size of the pattern was chosen to give a field of view of $2 \mathrm{~m}$ at source-to-mask distances of between 1.5 and $3 \mathrm{~m}$, depending on the separation of the mask and detector. For the MURA pattern, the positions of the closed and open portions of the mask can be interchanged by rotating the mask 90 degrees. By measuring in both of these configurations (referred to as "mask" and "antimask", respectively) and taking the difference, background counts that did not originate in the field of view will cancel, even if they are not uniformly distributed across the detector. In the present imager, rotation between mask and antimask configurations has been automated.

The neutron detector portion of the imager consists of a panel of nine individual detectors that are packed closely together in a $3 \times 3$ array to give a total area of $33.7 \times 33.7 \mathrm{~cm}^{2}$ and are composed of 576 individual pixels in a 24 pixel $\times 24$ pixel array. The $24 \times 24$ array of detector pixels is sufficient to double-sample the apertures in the mask base pattern. The detectors and their performance have been described previously [5], but a brief description is repeated here for clarity. The active volume of a single detector module, typically referred to as the "pixel block," consists of a $10.8 \times 10.8 \times 5 \mathrm{~cm}^{3}$ volume of scintillator EJ-299-34 segmented by 3M Vikuiti reflector into an $8 \times 8$ array of $1.35 \times 1.35 \times 5 \mathrm{~cm}^{3}$ optically isolated pixels of plastic scintillator. The pixels are viewed through a $28-\mathrm{mm}$-thick segmented acrylic light guide by four $52 \mathrm{~mm}$ Hamamatsu R7724-100 super bialkali photomultiplier tubes (PMTs) whose shared response determines the pixel of interaction. The detector module is placed in a housing whose external dimensions in the imaging plane are $11.2 \mathrm{~cm} \times 11.2 \mathrm{~cm}$. The active area therefore comprises $92 \%$ of the total. Photographs of the constituent scintillator pixel array, light guide, assembled active components, and assembled detector in its housing are shown in Fig. 2.

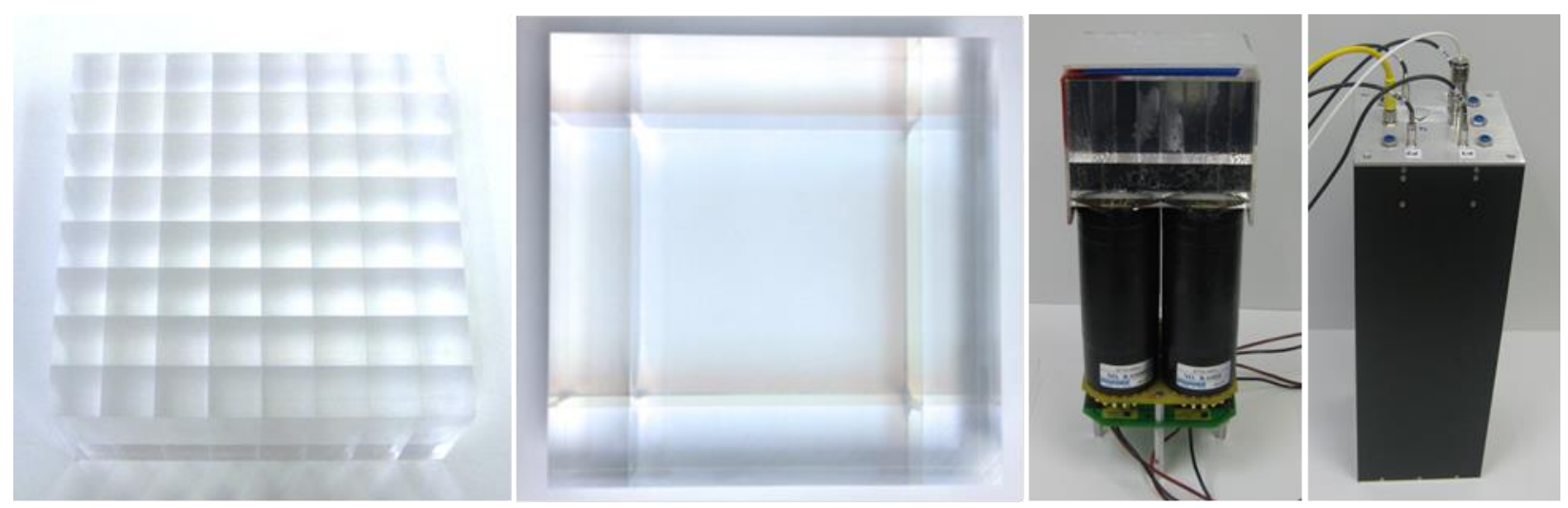

Fig. 2. The components and assembly of a single detector module. From left to right, the pixel array, light guide, assembled detector, and assembled detector in its housing are shown.

Previous work identified that uncertainty in the distance to a neutron source would be a major source of error in the inferred source strength, and therefore the mass of plutonium holdup [2]. Particularly for a compact imager with a small mask-to-detector spacing, the most accurate method for inferring the distance to a source is to use parallax between two or more successive measurements in which the imager was repositioned a known amount between measurements. A number of methods are possible for accurately determining the distance the imager was moved between each measurement. For instance, the imager could be painstakingly positioned by hand in predetermined locations, the imager could be positioned via automated motion control along a track to predetermined locations, or the imager could be roughly positioned by hand and its position and orientation for each measurement determined with respect to fiducial points in the scene via optical depth data. For the present proof-of-concept measurements, hand positioning in predetermined locations was used. For the longer term, rough hand positioning followed by accurate determination of the position and orientation of the imager for each measurement would be more flexible and easy to use and would require minimal infrastructure. 
For this purpose, a Microsoft Kinect ${ }^{\circledR}$ camera has been mounted in front of the center of the coded aperture mask. The Kinect ${ }^{\circledR}$ records photographs and depth images of the field of view that can be registered to the individual neutron images; the camera itself and thin carbon fiber mounting post minimally attenuate the neutrons. It is anticipated that the depth data from a combination of images will eventually be used both to identify the three-dimensional geometry of the measurement scene (where visually accessible) and to infer the position of the imager in each view with respect to fiducial points, thereby enabling the combination of data to determine source position from imaging measurements in multiple arbitrary positions. Each of the images recorded by the Kinect ${ }^{\circledR}$ has $640 \times 480$ pixel resolution and spans a nominal 58.5 degree horizontal field of view. The depth data has a range of $5 \mathrm{~m}$ and a nominal precision of $1.5 \mathrm{~mm}$ at $50 \mathrm{~cm}$. 


\section{THE MOCK HOLDUP MEASUREMENTS}

A series of mock holdup measurements were performed using the fast-neutron imager. A number of ducts, pipes, junctions, and a HEPA house are used as training aids in the ORNL Safeguards Laboratory. Three of these fixtures, the large L-duct, the HEPA filter house, and the pipe array, were chosen as exemplars of fuel cycle facility equipment for use with the mock holdup measurements. Photographs of the (left) L-duct, (center) HEPA filter house, and (right) the pipe array are shown in Fig. 3.
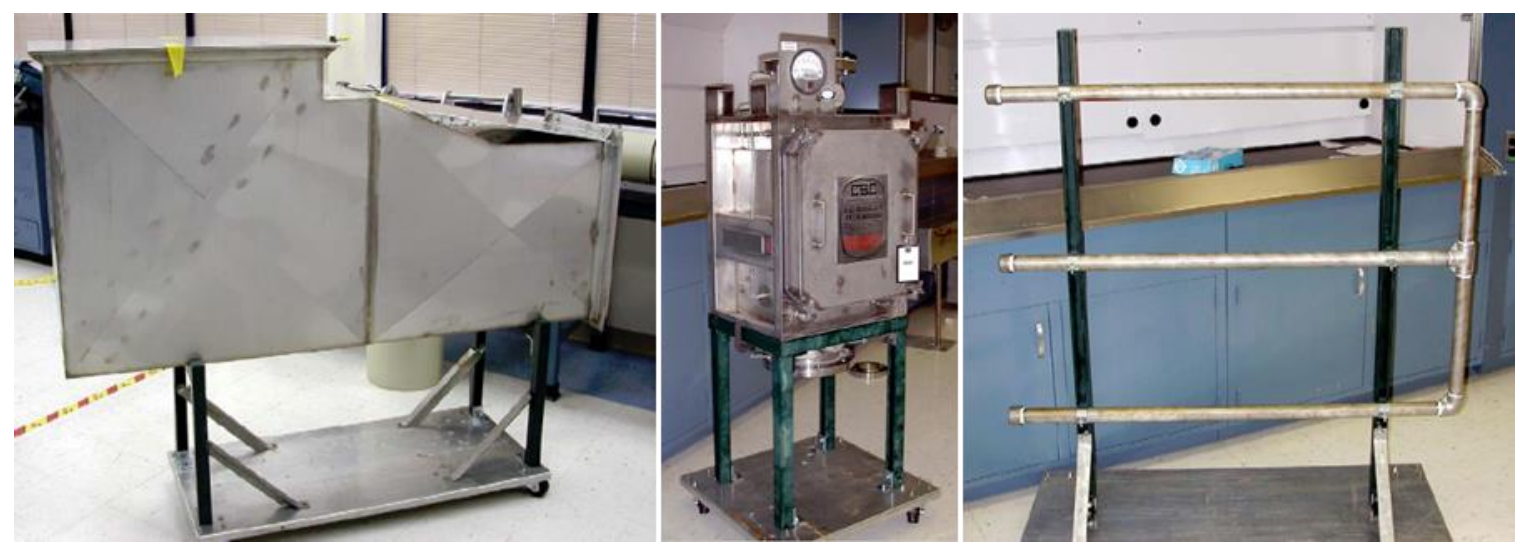

Fig. 3. Photographs of the large L-duct, HEPA filter house, and pipe array used for mock holdup measurements.

Holdup configurations were mimicked by placing known-intensity ${ }^{252} \mathrm{Cf}$ sources in the fixtures. For the present work, five identical ${ }^{252} \mathrm{Cf}$ sources were used. Each of the sources consists of a $0.25 \mathrm{in}$. diameter by $0.5 \mathrm{in}$. long pellet with an activity of $5 \mu \mathrm{Ci}$ (as of August 2013) for a neutron emission rate of 22,000 per second. The $\mathrm{PuO}_{2}$ from typical commercial reactor fuel has a neutron emission rate of approximately 650 neutrons per second per gram (approximately 20 neutrons per second per gram per exposure (in $\mathrm{GWd} / \mathrm{MTU})$ ) [adapted from 6,7]. For this activity level, each of the ${ }^{252} \mathrm{Cf}$ sources is equivalent to a neutron source strength of $33 \mathrm{~g}$ of commercial reactor-grade $\mathrm{PuO}_{2}$. In this conversion, no correction is made for different neutron detection efficiencies that might result from the differences in emitted neutron energies between $\mathrm{PuO}_{2}$ and ${ }^{252} \mathrm{Cf}$.

For the measurements, the training fixtures were arranged with the pipe array closer to the imager than the HEPA filter house and L-duct so that neutron sources could potentially be above, below, and behind one another while still being contained within the fixtures. The layout of the fixtures in the mock holdup scene is shown schematically in Fig. 4. 


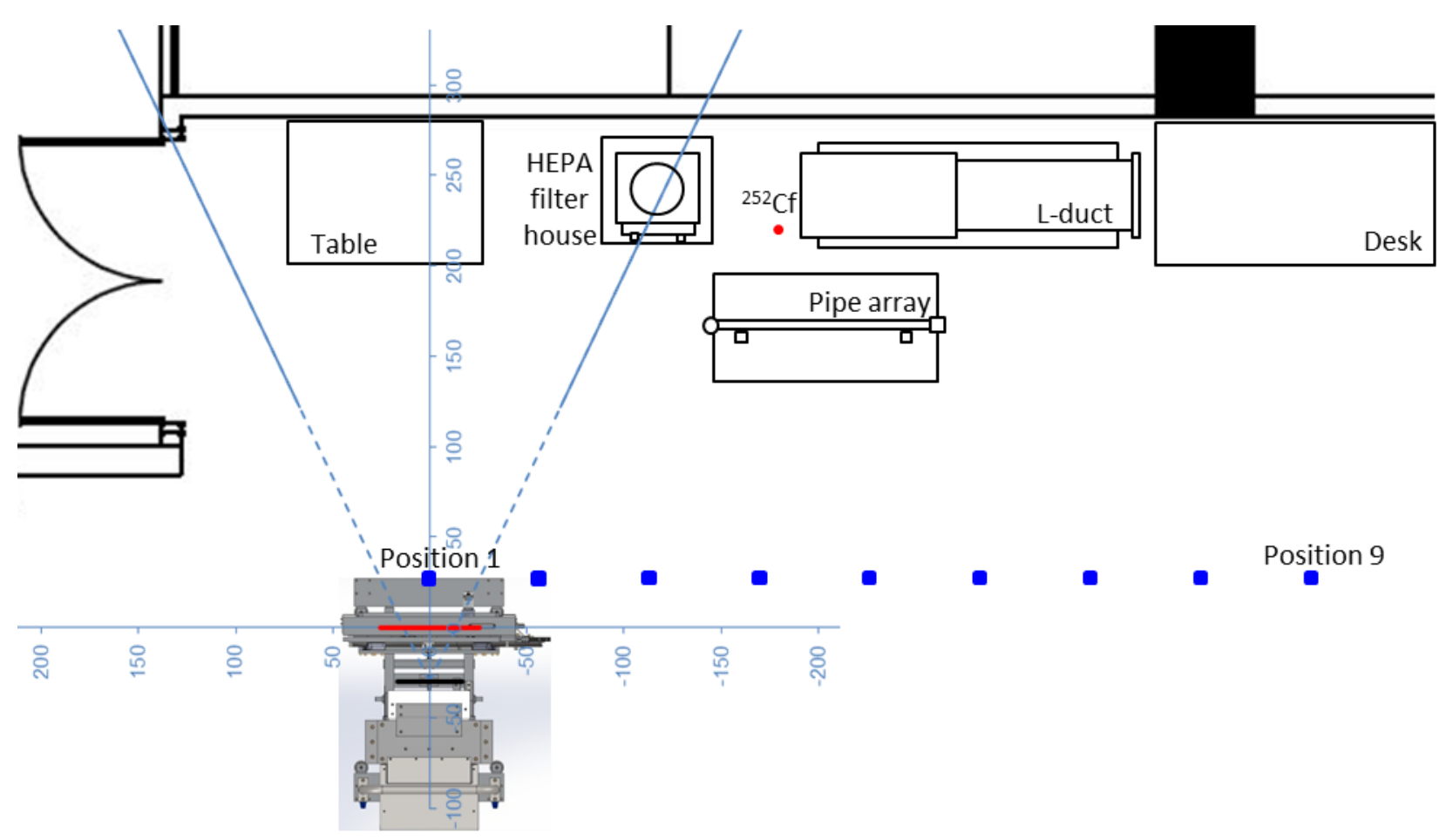

Fig. 4. Layout of the mock holdup measurement scene. The locations of the HEPA filter house, pipe array, and L-duct are indicated along with the nine scan positions of the imager and the location of the ${ }^{252} \mathrm{Cf}$ source for the first measurement scene.

For these measurements, the fast-neutron imager was configured with a $5.1 \mathrm{~cm}$ thick mask and a maskdetector separation of $30 \mathrm{~cm}$, yielding a $200 \mathrm{~cm}$ field of view at a distance of $195 \mathrm{~cm}$ from the center of the mask. In order to scan the entire scene for fast-neutron sources, the fast-neutron imager was sequentially moved to each of nine positions separated from the previous position by $60 \mathrm{~cm}$. These positions are shown in the floor plan of Fig. 4 as blue squares whose endpoints are labeled "position 1" and "position 9." The location and field of view for position 1 of the imager are also shown on this floor plan. In the scan of a particular scene, the imager measured for 20 minutes at each position. A total of six scenes were measured. Two of these scenes were relatively uncomplicated, having the five ${ }^{252} \mathrm{Cf}$ sources located in a single location and two locations, respectively. These configurations will be considered in more depth. The remaining four scenes were more complicated, with the five sources distributed among the HEPA filter house and pipe array. For two of the complicated scenes, an additional and more intense source having an activity of $52 \mu \mathrm{Ci}$ and a neutron emission rate of 230,000 neutrons per second was placed $120 \mathrm{~cm}$ beyond the near side of the wall separating the laboratory used for the imaging scans from the neighboring space in order to determine whether its position could be identified, in addition to that of the others.

\section{Scene 1}

In the first scene, all five ${ }^{252} \mathrm{Cf}$ sources totaling an emission rate of 110,000 neutrons per second (comparable to $165 \mathrm{~g}$ of reactor-grade $\mathrm{PuO}_{2}$ ) were held in a common location by means of a ring stand. The position of this source is indicated on the floor plan in Fig. 4 by the red dot. A composite photograph of the scene was also produced using the nine individual photographs taken by the Kinect ${ }^{\mathrm{TM}}$ camera at each point in the scan. This image is shown in the upper panel of Fig. 5. The position of the ${ }^{252} \mathrm{Cf}$ neutron source in this picture is indicated by the red dot and accompanying red arrow. The grayscale image in the 


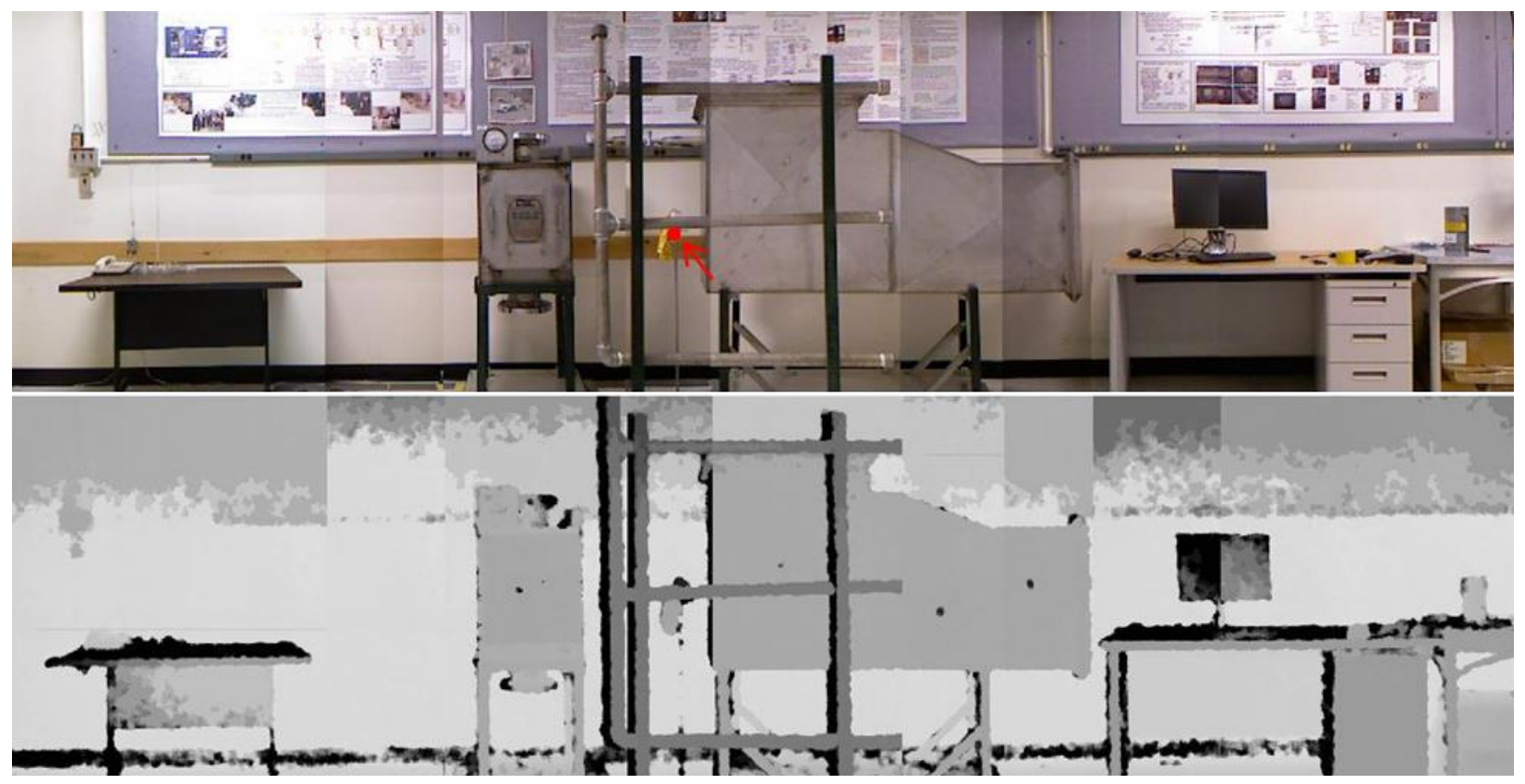

Fig. 5. A composite view of the first scene: (above) photograph and (below) depth image.

lower panel of Fig. 5 shows the corresponding depth image that later can be used to build the threedimensional geometry.

For each individual measurement in the scan of the first scene, the fast-neutron image was reconstructed for all distances between $100 \mathrm{~cm}$ and $500 \mathrm{~cm}$ and projected into a voxelized space that spanned the scene. A slice through the voxelized space that contains the height of the source is shown for the three measurement positions that contain the ${ }^{252} \mathrm{Cf}$ source in the field of view in (a) through (c) in Fig. 6. It can be seen that each measurement individually points to the neutron source. All nine views can be combined simply by adding the image data from each position and then dividing each voxel value by the number of measurements that contribute to it. This simple combined view, in which the position of the source is visually apparent, can be seen in Fig. 7. The streaks apparent at the edges of this combined view of the scene are artifacts associated with the response of the imager to a source that is outside the field of view but still casts a partial shadow of the aperture mask onto the detector. 

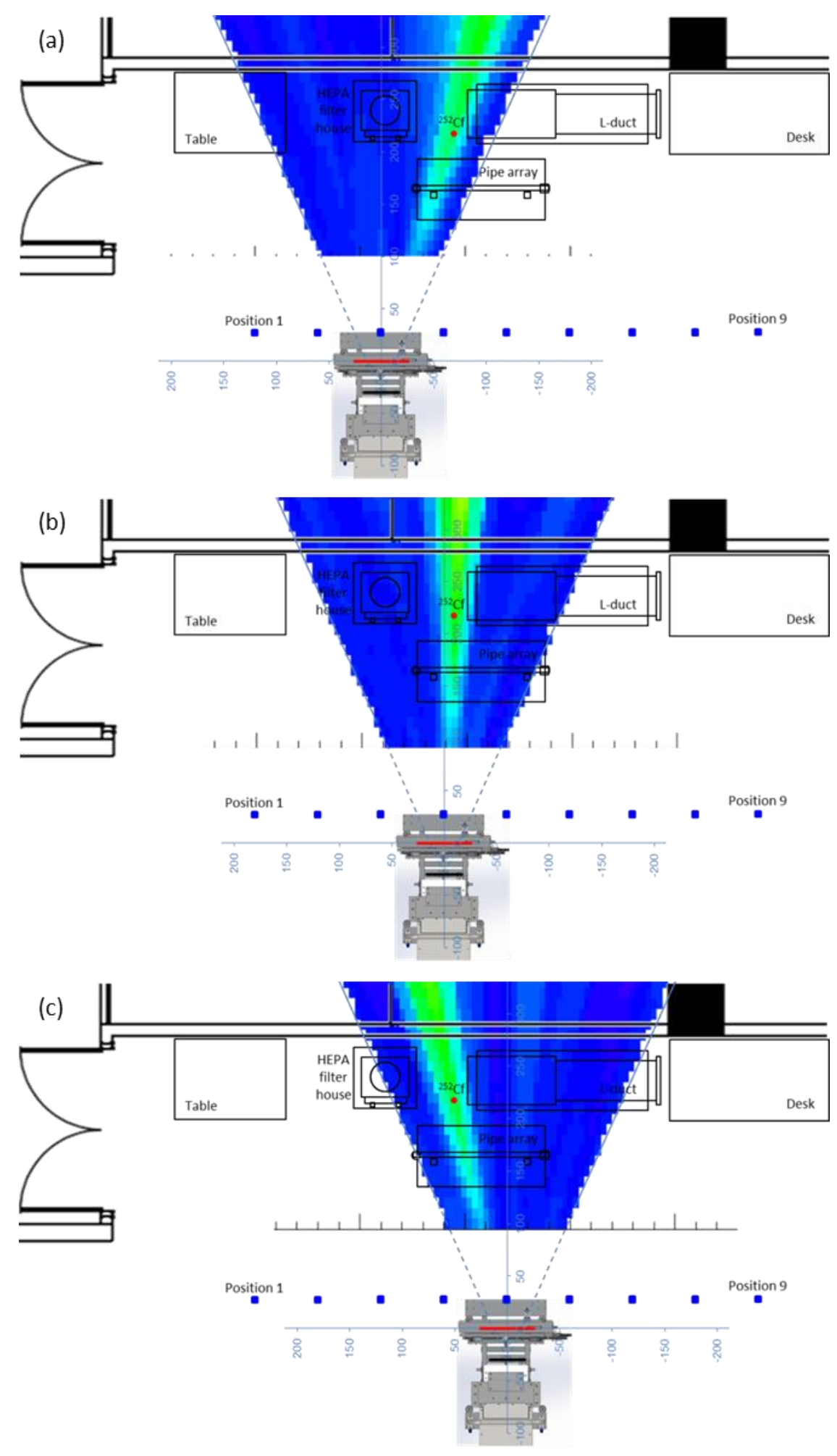

Fig. 6. Individual coded-aperture images as a function of distance from the imager for a slice in height that includes the neutron source. The images are overlaid on the floor plan where the position of ${ }^{252} \mathrm{Cf}$ source is shown. 


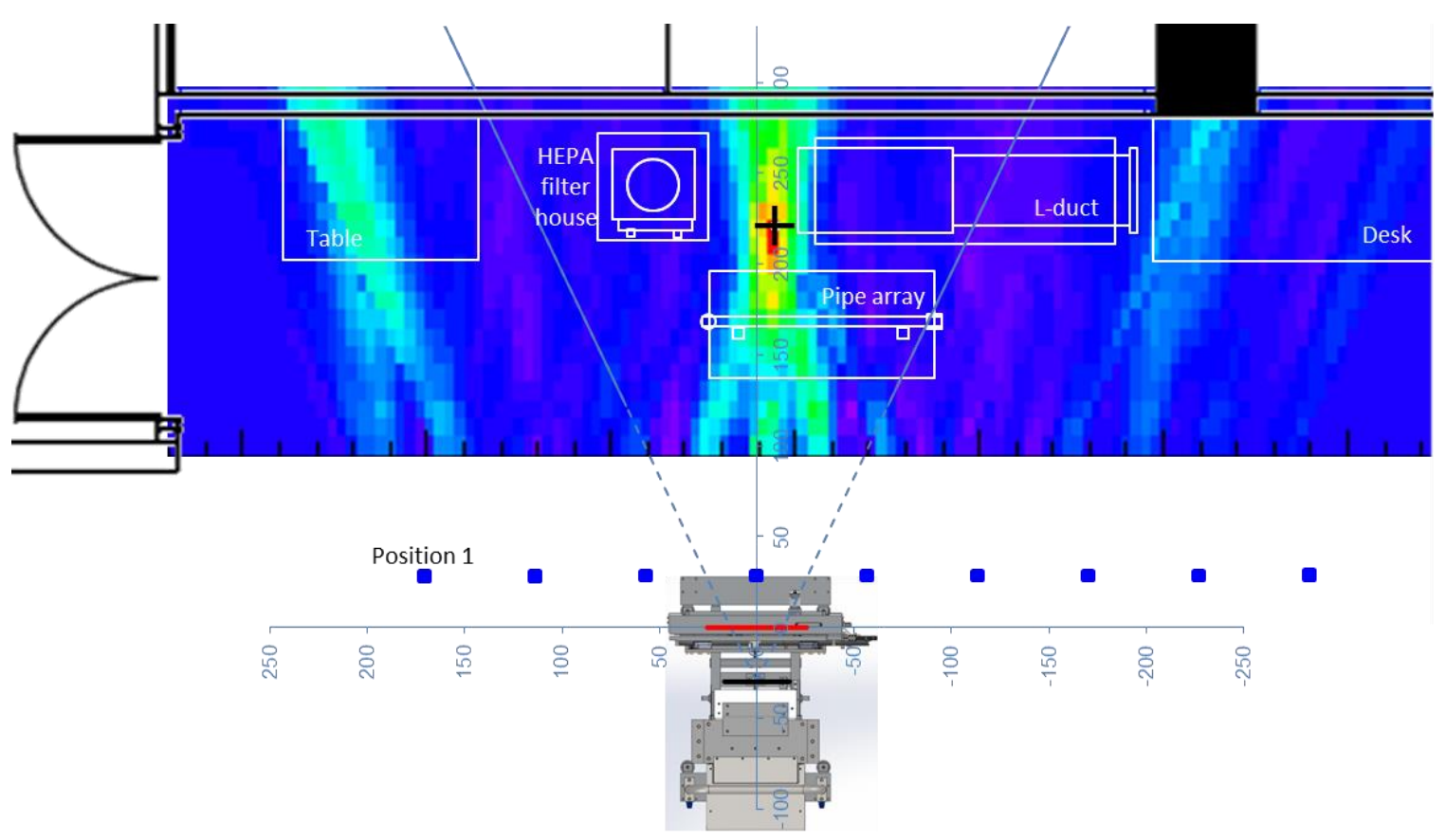

Fig. 7. A combined image of the nine individual measurements for scene 1 . The position of the ${ }^{252} \mathrm{Cf}$ neutron source is indicated by the "+". The streaks at the edges of the scene are artifacts associated with the response to a source outside the field of view.

\section{Scene 2}

In the second scene, two of the five ${ }^{252} \mathrm{Cf}$ sources were removed from the ring stand and moved to a second location closer to the imager and adjacent to the pipe array. The emitted neutron rate from the sources at the original location consequently totaled 66,000 neutrons per second, and those from the second location totaled 44,000 neutrons per second. The combined image of the second scene is shown overlaid on the floor plan, along with the neutron source positions marked by "+" symbols, in Fig. 8. 


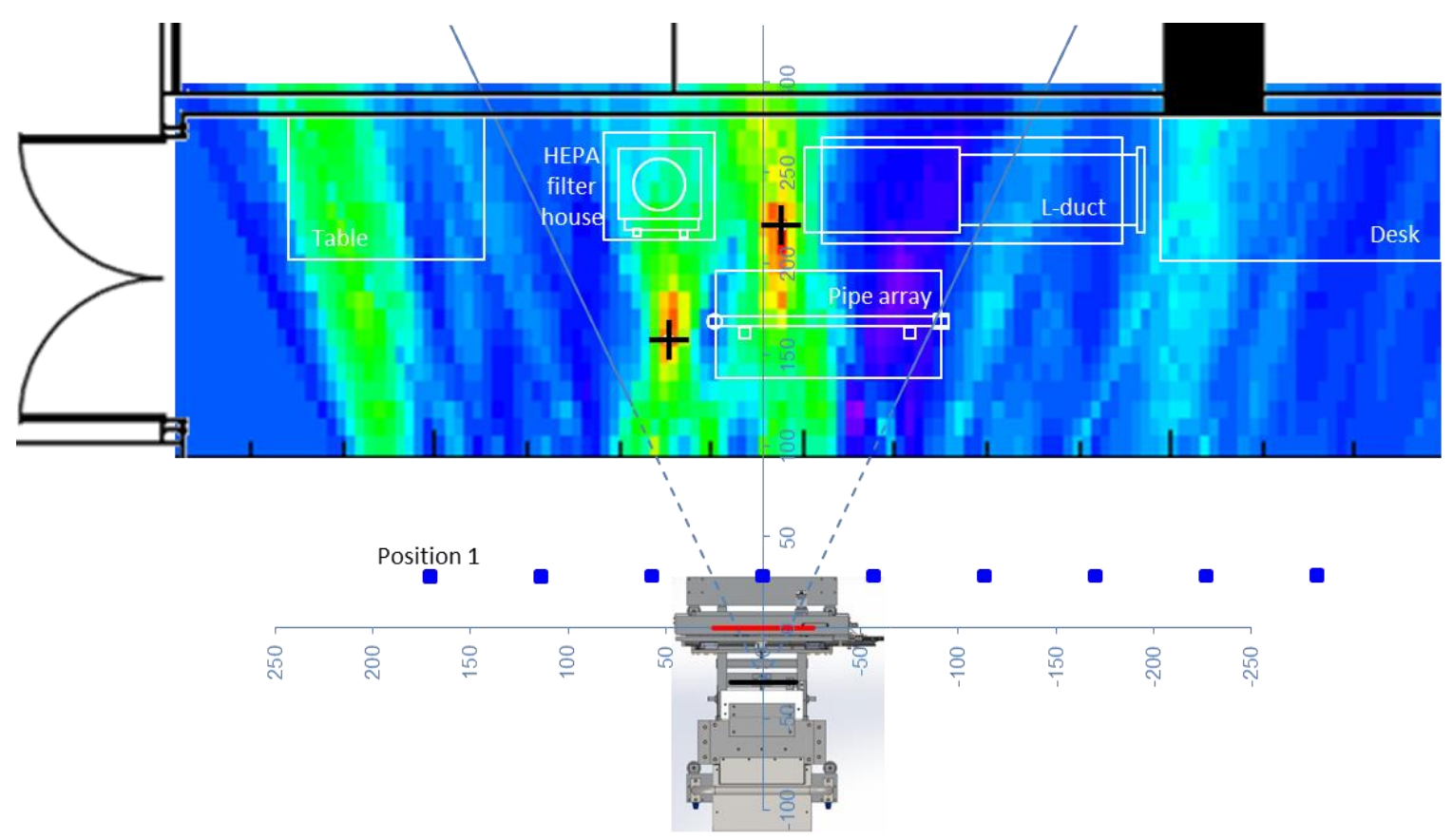

Fig. 8. A combined image of the nine individual measurements for scene 2 . The positions of the two ${ }^{252} \mathrm{Cf}$ neutron sources are indicated by “+” symbols.

\section{Scene 3}

In the third scene, the five ${ }^{252} \mathrm{C}$ f sources were placed inside the pipe array and HEPA filter house. Three sources were taped at positions along a thin aluminum rod so that when the rod was inserted in the vertical pipe of the pipe array, the sources were positioned at the locations of the two tees and one elbow. The HEPA filter house, as its name suggests, houses a HEPA filter cartridge that is $30 \mathrm{~cm}$ on one side and seals within the filter house. In the HEPA filter house, a surrogate filter cartridge box constructed of plywood replaced the filter cartridge. The surrogate box has slots for positioning each of three $28 \mathrm{~cm} \times 28$ $\mathrm{cm} \times 0.22 \mathrm{~cm}$ aluminum plates on which ${ }^{252} \mathrm{Cf}$ sources were mounted as desired using adhesive tape. As viewed from the front of the filter house, one source was positioned in the near bottom right corner, and one was positioned in the far upper left corner. The source positions are indicated by red dots on the composite photograph in Fig. 9.

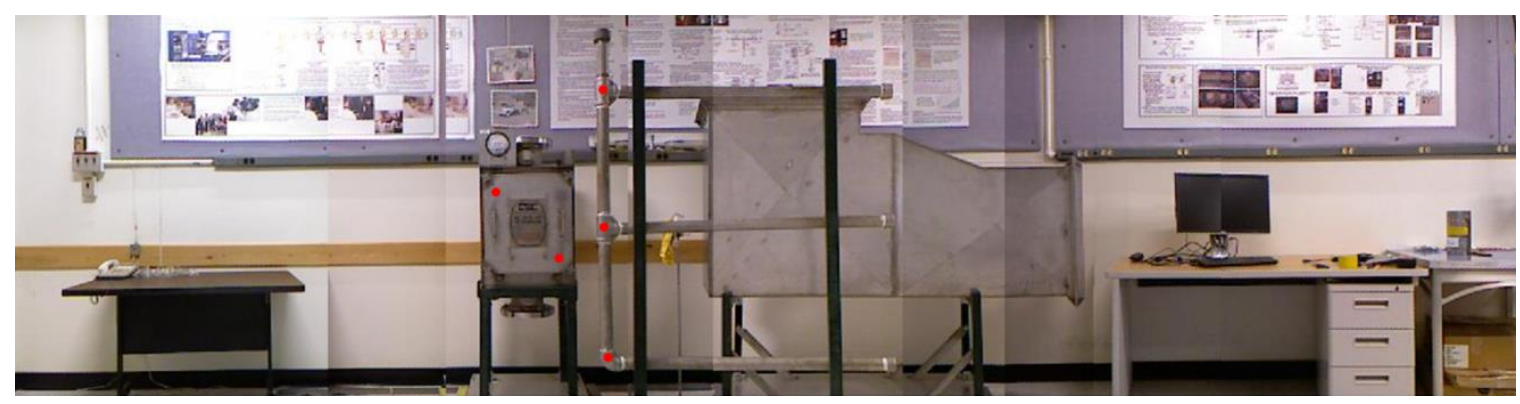

Fig. 9. Composite view of scene 3 with the positions of the neutron sources indicated by the red dots. 
The combined image for the nine measurements of the third scene selected for heights near that of the center pipe of the pipe array is shown overlaid on the floor plan in Fig. 10. The positions of the three neutron sources in this height range are marked by "+" symbols. Note that contrast in the image is good for the near source but poorer for the sources at longer distances. Additional analysis will need to be performed to reliably extract distances to sources that are shadowed in this way by nearer sources that are comparable in strength or stronger.

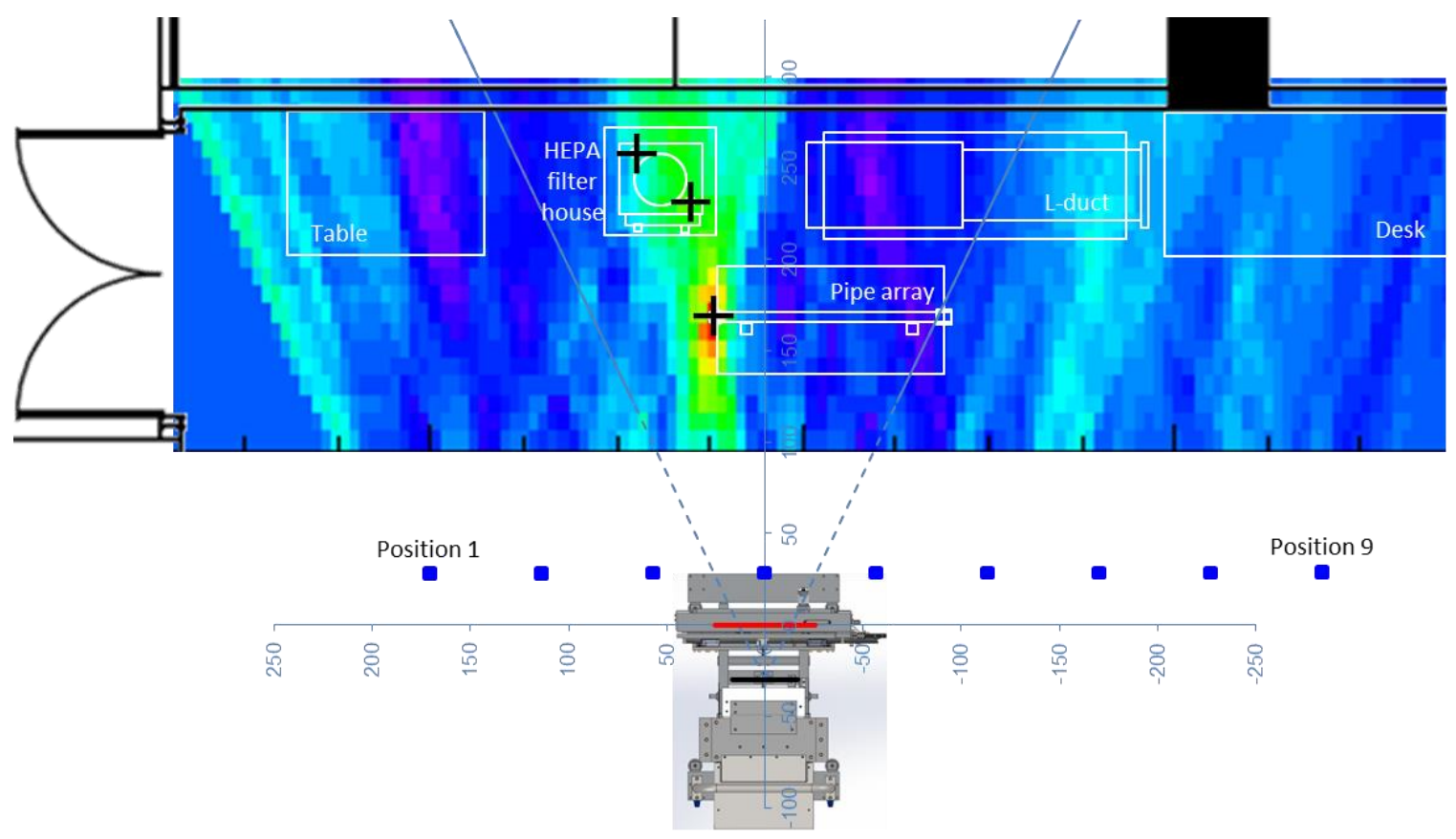

Fig. 10. A combined image of the nine individual measurements for scene 3 . The positions of the three ${ }^{252} \mathrm{Cf}$ neutron sources within the height range for this image are indicated by "+" symbols.

\section{Scene 4}

The fourth scene is identical to the third scene with the addition of a strong source in the next room. The combined image for the nine measurements of the fourth scene selected for heights near that of the center source on the pipe array is shown overlaid on the floor plan in Fig. 11. The positions of the four neutron sources in this height range are marked by "+" symbols. Note that contrast is good for the source in the next room because it is stronger than the other sources by about an order of magnitude. 


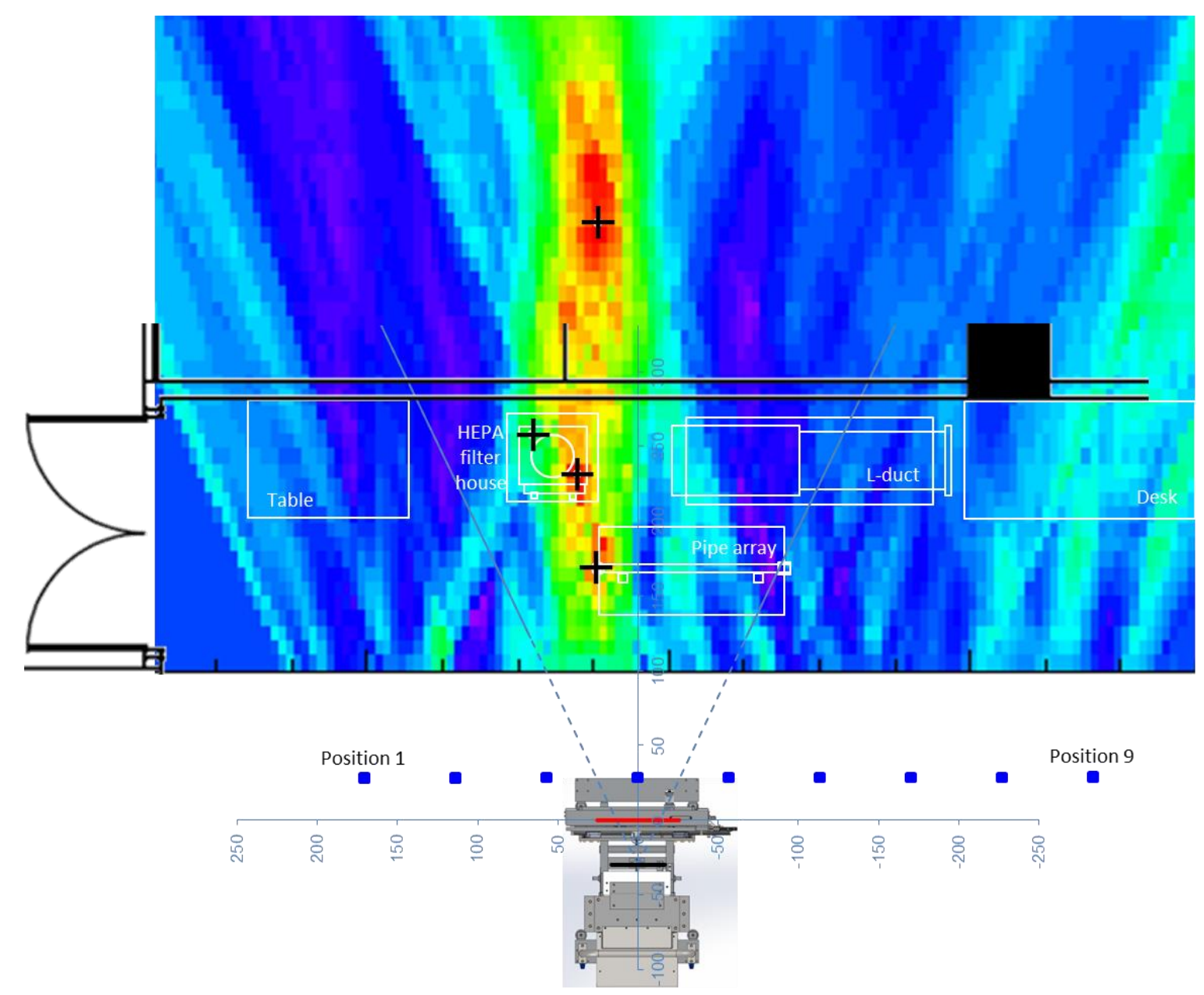

Fig. 11. A combined image of the nine individual measurements for scene 4. The distribution of the sources is identical to that of scene 3 except for the addition of a strong source in the next room. The positions of the four ${ }^{252} \mathrm{Cf}$ neutron sources within the height range for this image are indicated by "+" symbols.

\section{Scene 5}

In the fifth scene, the five ${ }^{252} \mathrm{Cf}$ sources were again placed inside the pipe array and HEPA filter house. Four sources were taped at equidistant positions along a thin aluminum rod (to somewhat approximate a line source), and the rod was inserted in the center horizontal pipe of the pipe array. A single source was placed in the HEPA filter house and positioned at the center of the filter box. The source positions are indicated by red dots on the composite photograph in Fig. 12.

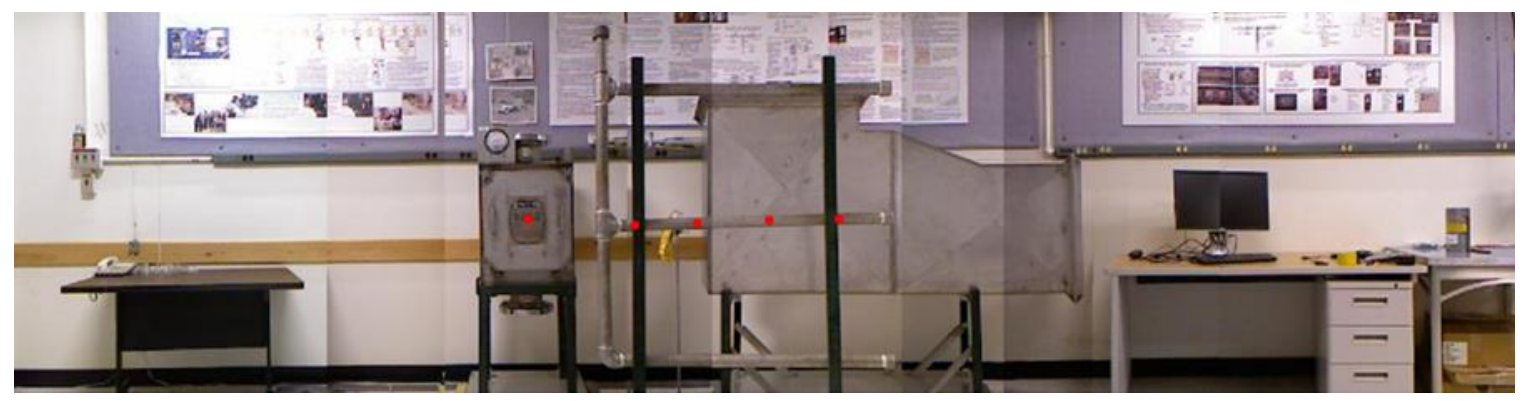

Fig. 12. Composite view of scene 5 with the positions of the neutron sources indicated by the red dots. 
The combined image for the nine measurements of the fifth scene selected for heights near that of the center pipe of the pipe array is shown overlaid on the floor plan in Fig. 12. The positions of the five neutron sources are marked by "+" symbols. Note that because of the number of sources, accidental crossings of rays from different true source positions suggest the presence of ghost sources that are not present, such as the darkest point at about $220 \mathrm{~cm}$ in front of position 4 . Additional analysis will need to be performed to reliably extract distances to sources in complicated images with many sources. In some cases, more measurement positions may be needed in order to eliminate ambiguities.

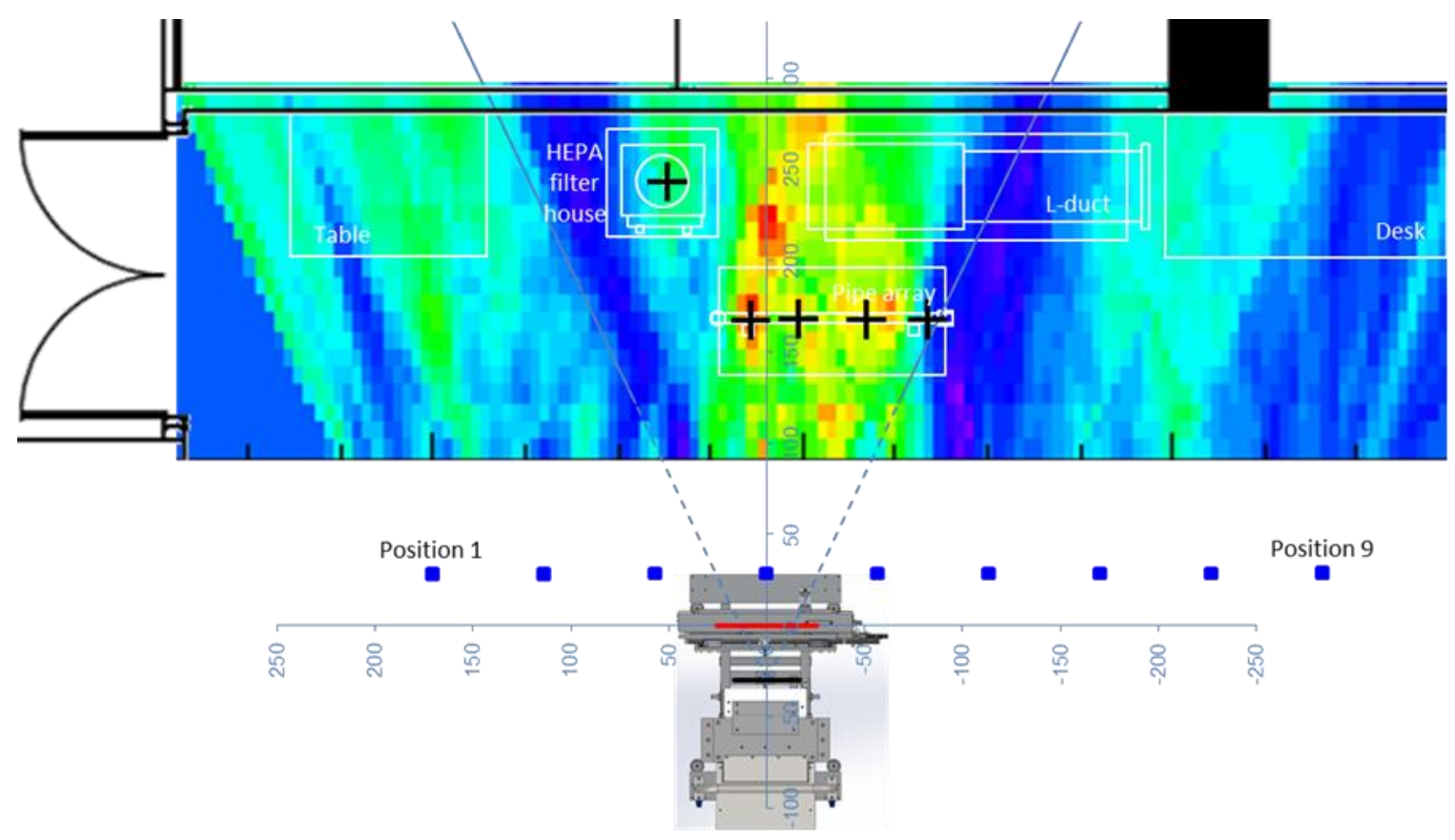

Fig. 13. A combined image of the nine individual measurements for scene 5. The positions of the five ${ }^{252} \mathrm{Cf}$ neutron sources within the height range for this image are indicated by "+" symbols.

\section{Scene 6}

The sixth scene is identical to the fifth scene with the addition of a strong source in the next room. The combined image for the nine measurements of the sixth scene selected for heights near that of the center pipe of the pipe array is shown overlaid on the floor plan in Fig. 14. The positions of the four neutron sources in this height range are marked by "+" symbols. Note that contrast is good for the source in the next room because it is stronger than the other sources by about an order of magnitude. 


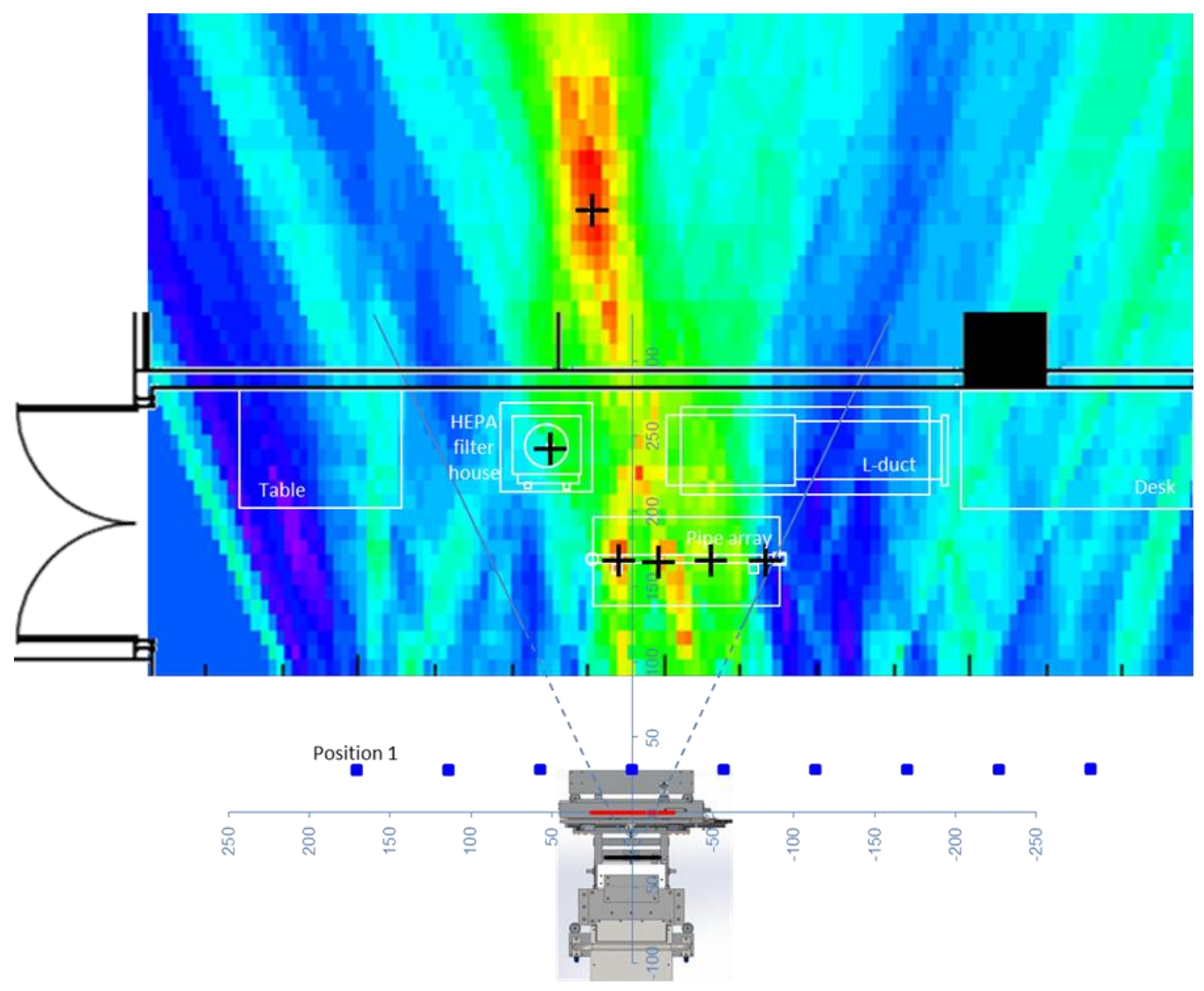

Fig. 14. A combined image of the nine individual measurements for scene 6. The distribution of the sources is identical to that of scene 5 except for the addition of a strong source in the next room. The positions of the six ${ }^{252} \mathrm{Cf}$ neutron sources are indicated by “+” symbols. 


\section{ANALYSIS}

For simple source configurations, the average response of a number of images can readily identify the presence and location of a few sources of similar strength. However, for more complicated scenes having a larger number of sources and disparate source strengths, it will generally be difficult to assess the data "by eye." Instead, more complicated analysis is required, and additional measurements may be required to resolve ambiguities. For the present work, it is sufficient to consider measuring distances to sources for simple scenes involving one or two sources.

In scene 1, the single neutron source is recorded in the field of view in at least three views (from positions 3,4 , and 5). For each of these views, the centroid position of the source intensity was extracted from the image at each reconstructed distance. The reconstructed images for position 3, 4, and 5 (as a function of depth) are shown in the first column of Fig. 15, along with the centroid positions and best-fit lines to the sets of centroids. In the second column of Fig. 15, the lines are plotted on the combined image for all of the measurements of scene 1. On the lower right, a close-up of the region where these lines intersect is shown, in this case identifying the distance to the source as $225 \mathrm{~cm}$ from the imager mask center.
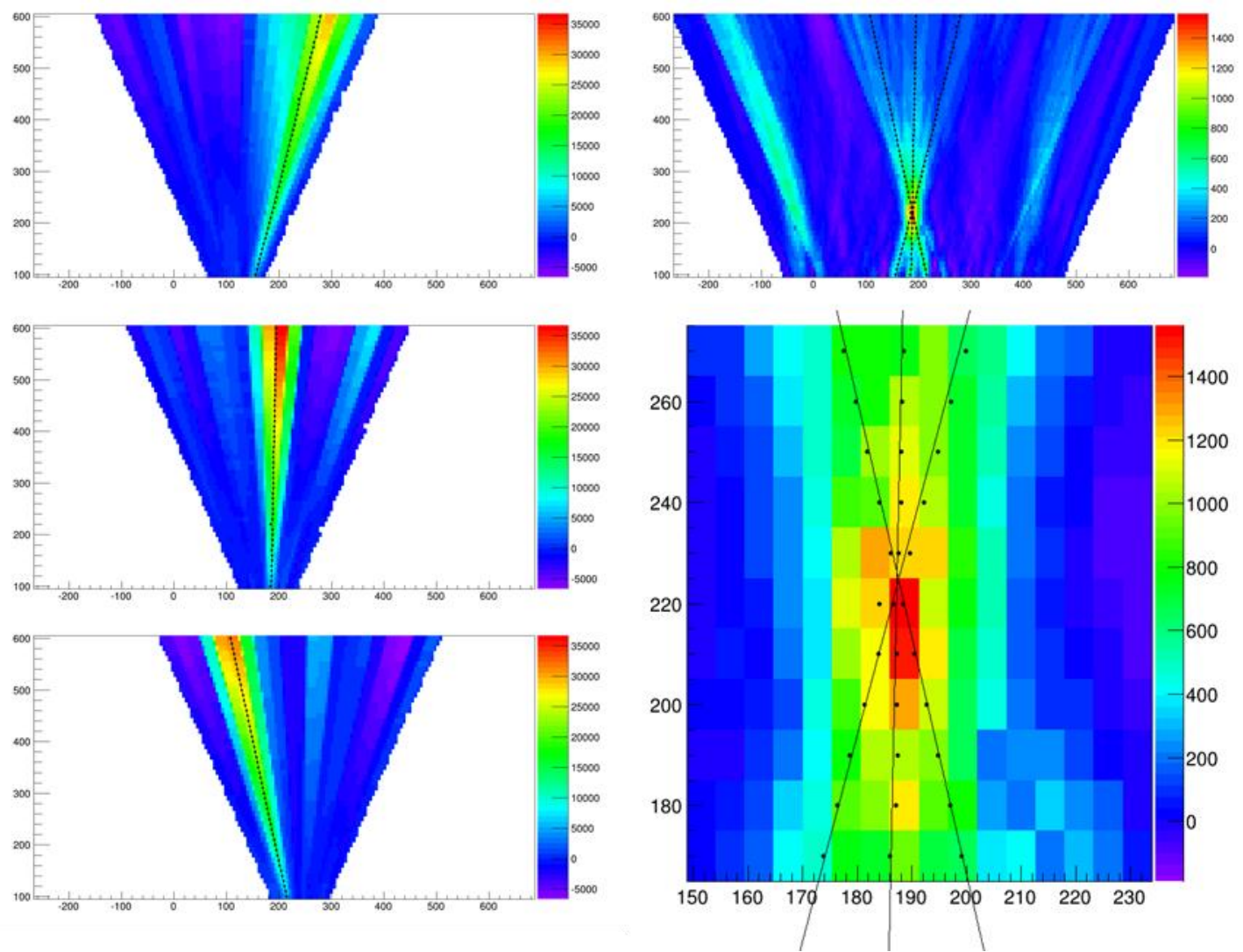

Fig. 15. Locating the source in the first scene.

For scene 2, similar plots were made, although in this case there were four contributing views, two of which recorded a single source and two of which recorded both sources. The combined image for all of the measurements in scene 2 along with the centroid positions and best-fit lines to the sets of centroids is shown in Fig. 16. For clarity, a zoomed image of the intersection points of the lines is shown on the righthand side of Fig. 16. These measurements identify the far source at a distance of $216 \mathrm{~cm}$ and the near source at a distance of $159 \mathrm{~cm}$. 

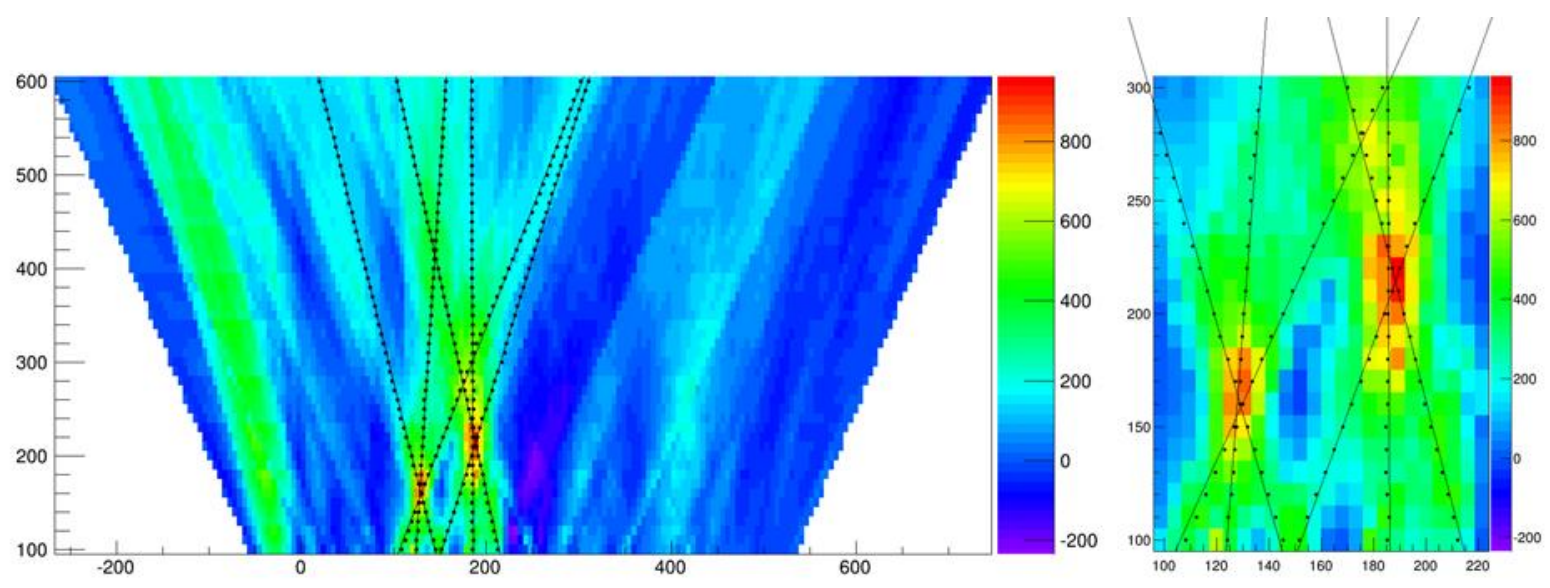

Fig. 16. Locating two sources in the second scene.

Both measurements that capture the same source give an independent measurement of the distance to the source, and the spread in these values gives an idea of the uncertainty in the distance. By including data from both scenes, the distance to the far source was determined to be $220 \pm 3 \mathrm{~cm}$ via the radiation measurements alone. Likewise, the distance to the nearer source was determined to be $158 \pm 3 \mathrm{~cm}$. For comparison, the distances as measured with a tape measure corresponded to $219.5 \mathrm{~cm}$ and $157.5 \mathrm{~cm}$, respectively. The errors in distance for the radiation measurements to the two sources turned out to be the same (despite their different distances) because the longer distance of the one source was offset by more measurements of its distance. For these measurements, the inferred errors in distance are consistent with the accuracy with which the position and direction of the imager could be set by hand. 


\section{SUMMARY}

ORNL has constructed a new, compact fast-neutron coded aperture imager intended for use in performing quantitative measurements of plutonium holdup at fuel-cycle facilities. The design has been chosen to reduce cost, to achieve a more compact size for the imager, and to favor sensitivity over angular resolution. The imager is envisioned to seamlessly combine arbitrary neutron images exposed in a scene in order to deduce the three-dimensional position and activity of the sources. Thus far, the imager has been built, proof-of-concept imaging scans of simple and complicated scenes have been performed, and scan data have been combined to infer the source distance for simple source configurations. The errors in these distance determinations are consistent with the accuracy with which the position and direction of the imager was set by hand. Increased accuracy in distance determination is expected following implementation of automated motion along a track, or by inferring the exact position and orientation of the imager by means of depth data from the Kinect ${ }^{\circledR}$ camera. 


\section{REFERENCES}

[1] N. Zaitseva, B. L. Rupert, I. PaweŁczak, A. Glenn, H. P. Martinez, L. Carman, M. Faust, N. Cherepy, and S. Payne, "Plastic scintillators with efficient neutron/gamma pulse shape discrimination," Nuclear Instruments and Methods in Physics Research A 668, 88 (2012).

[2] P. Hausladen, J. Newby, F. Liang, and M. Blackston, A Deployable Fast-Neutron Coded-Aperture Imager for Quantifying Nuclear Material, ORNL/TM-2013/248.

[3] P. A. Hausladen, M. A. Blackston, E. Brubaker, D. L. Chichester, P. Marleau, and R. J. Newby, Fast-Neutron Coded-Aperture Imaging of Special Nuclear Material Configurations, 53rd Annual Meeting of the INMM, Orlando, FL, USA, 2012.

[4] P. Hausladen, M. Blackston, F. Liang, and J. Newby, Measurements and Analysis of Mock Holdup Configurations Using Fast-Neutron Imaging, ORNL/TM-2012/400.

[5] S. R. Gottesman and E. E. Fenimore, "New family of binary arrays for coded aperture imaging," Applied Optics, 28(20), 4344-4352 (1989).

[6] S. P. Cerne, O. W. Hermann, and R. M. Westfall, Reactivity and Isotopic Composition of Spent PWR Fuel as a Function of Initial Enrichment, Burnup, and Cooling Time, ORNL/CSD/TM-244 (October 1987).

[7] D. Reilly, N. Ensslin, and H. Smith, editors, pp. 339 and 345 in Passive Nondestructive Assay of Nuclear Materials, NUREG/CR-5550 (March 1991). 